\title{
SPIRITUAL EDUCATIONAL; MODEL PEMBELAJARAN DALAM MELEJITKAN KECERDASAN RUHANI ANAK
}

\author{
Mistria Harmonis \\ Universitas Nurul Jadid, Paiton, Probolinggo \\ raraharmonis01@gmail.com \\ Tupliati \\ Universitas Nurul Jadid, Paiton, Probolinggo \\ tupliatizen@gmail.com
}

\begin{abstract}
This study aims to examine the Spiritual Educational learning model to jump-start children's spiritual intelligence. The research approach used is descriptive qualitative with case study type. The research site is located in Sinar Harapan Kindergarten, Probolinggo City. Data collection techniques by means of interviews and in-depth observation. Meanwhile, data analysis techniques include data reduction, data display, and data verification. The results of the study indicate that the Spiritual Educational learning model applies several Islamic learning activities on a regular and structured basis to boost children's spiritual intelligence. The implication is that it takes a variety of activities and a fun approach to be able to jump-start children's spiritual intelligence.
\end{abstract}

Keywords: Spiritual Educational, Children's Spiritual Intelligence 


\section{Pendahuluan}

Mengenalkan ajaran agama seperti keimanan harus dilakukan sejak dini kepada anak. Hal ini disebabkan kebutuhan spiritual menjadi hal yang tidak dapat dipisahkan mengingat manusia sebagai ciptaan Allah ${ }^{1}$. Dalam konteks ini, ajaran agama yang dimaksud adalah nilai-nilai rukun Islam, rukun Iman, dan nilai-nilai ihsan kepada anak. Ketiga nilai tersebut dapat menjadi pedoman bagi anak untuk belajar mengenali dan memahami perasaan diri sendiri dan orang lain dalam membangun hubungan dengan manusia dan Tuhannya ${ }^{2}$.

Untuk mengenalkan ajaran agama tersebut, bukan saja orangtua di rumah yang harus mengajarkannya. Dunia pendidikan formal juga mengemban tanggung jawab besar dalam mengembangkan kecerdasan spiritual anak. Imam al-Ghazali ${ }^{3}$ dalam kitab Ibya' 'Ulum ad-Din juga menyatakan bahwa kesempurnaan seseorang yang mengantarkan kedekatan diri pada Allah dan kebahagiaan dunia dan akhirat menjadi tujuan akhir dari proses pendidikan. Hal tersebut juga telah didukung dengan adanya Permendikbud No 137 pasal 10 ayat 2 yang menjelaskan bahwa nilai agama dan moral untuk tingkat usia anak meliputi kemampuan mengenal nilai agama yang dianutnya, beribadah, berperilaku jujur, penolong, sopan, hormat, sportif, menjaga kebersihan diri dan lingkungan, mengetahui hari besar agama, menghormati dan toleran terhadap agama orang lain ${ }^{4}$. Dengan demikian, lembaga pendidikan, terutama yang setingkat PAUD tidak hanya dituntut untuk membekali anak didiknya dengan materi calistung (membaca, menulis, dan berhitung) saja, tetapi juga harus mampu mengoptimalkan kecerdasan spiritual anak guna mencapai kesuksesan dunia dan akhirat ${ }^{5}$.

Hal itu sejalan dengan ayat Al Quran Surat At-Tahrim ayat 6 berikut ini.

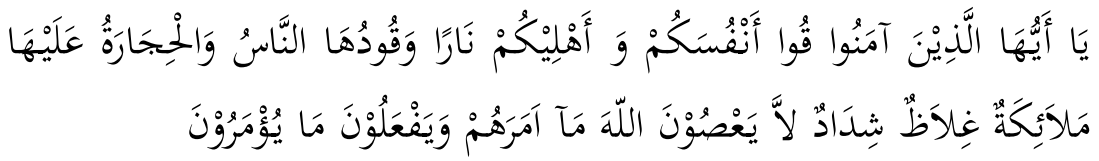

\footnotetext{
${ }^{1}$ Safrudin Aziz, "Pendidikan Spiritual Berbasis Sufistik," Dialogia: Jurnal Studi Islam Dan Sosial 15, no. 1 (2017): 131-50.

2 Ferdian Utama, "ESQ Way 165: Alternatif Metode Pengembangan Kecerdasan Emosi Dan Spiritual Anak," Journal of Early Childhood Care and Education 1, no. 1 (2018): 7, https://doi.org/10.26555/jecce.v1i1.59.

3 (dalam Wulandari et al., 2021)

${ }^{4}$ Nina Mariana, Abdul Azis, and Iwan Setiawan, "Pengembangan Kecerdasan Spritual Anak Usia Dini Melalui Homeschooling," Tarbiyah Al Aulad 4, no. 1 (2019): 27-44.

5 Novan Ardy Wiyani, "Optimalisasi Kecerdasan Spiritual Bagi Anak Usia Dini Menurut Abdullah Nashih Ulwan," ThufuL A: Jurnal Inovasi Pendidikan Guru Raudhatul Athfal, 2017, https://doi.org/10.21043/thufula.v4i2.2009.
} 
"Hai orang-orang yang beriman, jagalah dirimu dan keluargamu dari api neraka yang bahan bakarnya adalah manusia dan batu; penjaganya malaikat-malaikat yang kasar, keras, dan tidak. mendurbakai Allah terbadap apa yang diperintabkan-Nya kepada mereka dan selalu mengerjakan apa yang diperintabkan." ${ }^{6}$

Berdasarkan ayat tersebut, jelas bahwa kesuksesan di dunia tidak akan bernilai jika seseorang kelak tergelincir dalam siksa neraka. Itulah mengapa, orang tua, termasuk guru di sekolah, wajib untuk membekali pendidikan spiritual kepada anaknya.

Di era globalisasi seperti ini, pendidikan spiritual menjadi semakin penting untuk diajarkan sejak dini guna mencetak generasi bangsa yang memiliki pribadi saleh dan berkualitas dalam menghadapi krisis keruhanian. Sebab, arus globalisasi secara nyata telah membawa dampak negatif pada diri generasi muda seperti tawuran antarpelajar, pergaulan bebas, narkoba, maupun berbagai kerusakan moral lainnya ${ }^{7}$. Apabila tidak dicegah dan diantisipasi, tentu krisis ruhani yang menyebabkan kerusakan moral seperti itu akan berakibat fatal bagi negara di masa mendatang. Melalui pendidikan spiritual, anak diharapkan dapat menguasai IMTAK (iman dan takwa) dan IPTEK (ilmu pengetahuan dan tekonologi) dengan seimbang dan proporsional ${ }^{8}$. Selain itu, pendidikan spiritual menjadi hal dasar yang perlu dilakukan dalam membangun dan meningkatkan kekuatan hati untuk kemudian membentuk moral yang baik ${ }^{9}$.

Menurut para ahli, kecerdasan ruhani atau yang biasa disebut dengan spiritual intelligence merupakan kecerdasan primer yang bersandar pada hati manusia. Lebih lanjut lagi, Zohar dan Marshall ${ }^{10}$ menyatakan bahwa spiritual intelligence akan membuat seseorang senang dalam setiap mengakhiri suatu kegiatan. Hal tersebut sejalan dengan fungsi kecerdasan ruhani atau spiritual intelligence yang dapat membuat seseorang untuk berbuat sesuatu dengan penuh tanggung jawab serta diiringi rasa cinta pada Allah ${ }^{11}$. Hal ini yang kemudian membuat hati seseorang untuk

\footnotetext{
${ }^{6}$ At-Tahrim, “Al Quran,” in Penerbit Jabal, vol. 148, 2010, 148-62.

7 Inawati Asti, "Strategi Pengembangan Moral Dan Nilai Agama Untuk Anak Usia Dini," Jurnal Pendidikan Anak 3, no. 1 (2017): 51-64.

8 Abdul Hamid and Andi Fitriani, "Strategi Pendidikan Spiritual Dalam Mengantisipasi Dampak Globalisasi Pada Masyarakat,” Jurnal Al-Athfal 1, no. 2 (2019): 55-65.

${ }^{9}$ Ida Bagus Suradarma, "Revitalisasi Nilai-Nilai Moral Keagamaan Di Era Globalisasi Melalui Pendidikan Agama," Dharmasmrti: Jurnal Ilmu Agama Dan Kebudayaan 18, no. 2 (2018): 50-58, https://doi.org/10.32795/ds.v9i2.146.

${ }^{10}$ (dalam Wahyudi \& Agustin, 2018)

11 Marliza Oktapiani, "TINGKAT KECERDASAN SPIRITUAL DAN KEMAMPUAN MENGHAFAL AL-QUR'AN,” Tadz̧bib Akblak 01 (2020): 96.
} 
selalu yakin bahwa apa yang telah ditetapkan Allah adalah yang paling benar sehingga orang tersebut akan senantiasa berbuat benar.

Terkait dengan pentingnya pendidikan spiritual guna melejitkan kecerdasan ruhani, lembaga PAUD memiliki peranan penting dalam hal itu. Maka tidak heran ketika berbagai lembaga PAUD mengintegrasikan pendidikan spiritual dalam pembelajaran di kelas. Dalam hal ini, lembaga PAUD pada umumnya akan memberi pondasi awal kecerdasan ruhani dengan mengajarkan nilai-nilai keagamaan ${ }^{12}$. Sayang, pengajaran nilainilai keagamaan tersebut hanya sebatas teori. Padahal, untuk dapat mengembangkan kecerdasan ruhani anak diperlukan praktik yang menyenangkan agar nilai-nilai keagaaman tersebut lebih mengena dan membekas di hati anak ${ }^{13}$. Dengan begitu, apa yang ada dalam hati anak akan mempengaruhi tingkah laku anak.

Dalam menjawab problematika tersebut, TK Sinar Harapan berupaya menanamkan nilai-nilai spiritual melalui berbagai kegiatan edukatif. Kegiatan-kegiatan tersebut ada yang dilakukan secara rutin dan terjadwal maupun tidak terjadwal atau dilakukan spontanitas oleh guru. Oleh guru TK Sinar Harapan, kegiatan-kegiatan edukatif yang bersifat keruhanian tersebut diberi nama Spiritual Educational.

Guna memperoleh pembahasan yang utuh dan mendalam, penulis juga melakukan kajian terhadap beberapa penelitian terdahulu yang relevan dengan fokus penelitian ini. Pada penelitian pertama ${ }^{14}$ dijelaskan bahwa nilai-nilai spiritual akan lebih optimal diinternalisasikan apabila guru dapat menjadi teladan bagi peserta didiknya. Maknanya, guru tidak hanya dituntut untuk menguasai kompetensi professional, tetapi juga mampu untuk menguasai kompetensi kepribadian, sosial, dan pedagogik. Lalu pada penelitian kedua ${ }^{15}$ didapat hasil bahwa kecerdasan spiritual anak akan terbentuk apabila terdapat pendidikan akhlak. Sementara pada penelitian ketiga ${ }^{16}$ menjelaskan bahwa upaya penanaman aspek spiritual pada anak ketika pembelajaran jarak jauh adalah dengan memberikan tugas-tugas spiritual melalui Whatsapp seperti membaca Al Quran dan

\footnotetext{
12 Nurlaili, "Upaya Guru Dalam Meningkatkan Kecerdasan Spiritual Dengan Model Pembelajaran Sentra Di PAUD Mirage Gune," Jurnal Al Fitrah 2, no. 1 (2018): 229-41.

13 Suyadi, "Cerdas Dengan Spiritual Educational Games," in Saufa, 2015, 15.

${ }^{14}$ Nirwani Jumala Nirwani Jumala and Abubakar Abubakar, "Internalisasi Nilai-Nilai Spiritual Islami Dalam Kegiatan Pendidikan,” Jurnal Serambi Ilmu 20, no. 1 (2019): 160, https://doi.org/10.32672/si.v20i1.1000.

${ }^{15}$ Firdaus, "Membangun Kecerdasan Spiritual Islami Anak Sejak Dini," Al-Drikra 10, no. 1 (2016): 99-122.

16 Ervi Rosmayanti, "Upaya Penggunaan Model Pembelajaran Jarak Jauh Untuk Meningkatkan Aspek Spiritual Siswa SD 2 Medini," Al Hikmah: Journal Of Education 1, no. 1 (2020): 85-92, http://yphn.ac.id/ejournal/index.php/Alhikmah/index.
} 
membuat daftar hadir sholat Tarawih. Tentunya, guru juga meminta orangtua untuk mendampingi anak agar tugas tersebut dilaksanakan dengan baik.

Dari berbagai penelitian terdahulu di atas, terlihat jelas bahwa nilainilai spiritual akan tertanam apabila terdapat praktik nyata yang disertai teladan dari orangtua. Penelitian ini juga mengkaji model pembelajaran Spiritual Educational yang diterapkan di TK Sinar Harapan. Secara umum, kegiatan yang terintegrasi melalui pembelajaran ini memang berupa praktik nyata dari aspek spiritual. Namun, pelaksanaannya tidak hanya melalui kegiatan-kegiatan yang telah terencana dalam kurikulum, tetapi juga spontanitas dilakukan oleh guru sebagai selingan pembelajaran. Kegiataan yang spontanitas ini sebenarnya tergolong dalam model pembelajaran tematik yang dapat memuaskan rasa ingin tahunya terhadap lingkungan sekitar ${ }^{17}$, khususnya yang berkaitan dengan nilainilai spiritual. Pembelajaran yang dilakukan secara sistematis maupun spontanitas ini menjadi titik perbedaan dan kebaruan penelitian.

Uniknya, TK Sinar Harapan yang terletak di samping kantor kecamatan Kedopok ini bukanlah lembaga pendidikan yang berada di bawah naungan yayasan Islam atau pondok pesantren. Walau demikian, TK Sinar Harapan berupaya kuat untuk membekali anak didiknya dengan pendidikan agama, yakni dengan mengadakan pembelajaran Spiritual Educational.

Berdasarkan pemaparan di atas, penelitian ini penting untuk dilakukan guna mengetahui secara mendalam terkait model pembelajaran Spiritual Educational yang diterapkan di TK Sinar Harapan guna melejitkan kecerdasan spiritual/ruhani anak. Melalui model pembelajaran tersebut, anak belajar untuk melalukan sesuatu dengan penuh tanggung jawab yang didasari rasa cinta pada Allah. Dengan begitu, anak dapat tumbuh menjadi pribadi yang saleh dan tidak mudah terpengaruh oleh dampak negatif globalisasi.

Dalam mengkaji materi terkait Spiritual Educational sebagai model pembelajaran guna melejitkan kecerdasan ruhani anak, penulis menggunakan pendekatan kualitatif dengan jenis penelitian studi kasus. Pendekatan kualitatif dipilih guna mendeskrispikan dengan rinci dan mendalam mengenai sebuah kondisi dalam suatu konteks mengenai apa yang terjadi ${ }^{18}$. Adapun penggunaan jenis penelitian studi kasus menurut

${ }^{17}$ Nafia Wafiqni and Siti Nurani, "Model Pembelajaran Tematik Berbasis Kearifan Lokal," Al-Bidayah: Jurnal Pendidikan Dasar Islam 1, no. 2 (2018), https://doi.org/10.31227/osf.io/yv5u2.

18 Nugrahani Farida, Metode Penelitian Kualitatif Dalam Penelitian Pendidikan Babasa, Grasindo, vol. $\quad 1, \quad 2014, \quad$ http://ejournal.usd.ac.id/index.php/LLT\%0Ahttp://jurnal.untan.ac.id/index.php/jpdpb/articl 
Stake bermaksud untuk mengurai keunikan dan kekhasan karakteristik dari kasus yang dijadikan objek penelitian ${ }^{19}$. Oleh sebab itu, teknik pengumpulan data yang digunakan dalam penelitian ini yakni observasi, wawancara mendalam, dan dokumentasi sebagai pendukung kelengkapan data.

Lokasi penelitian ini berada di TK Sinar Harapan, kelurahan Jrebeng Wetan, kecamatan Kedopok, Kota Probolinggo. Sumber data dalam penelitian ini didapat dari hasil wawancara terhadap informan Syamsul Ariefin, M.Pd selaku kepala TK, Vivin Umami, S.Pd dan Urfiani, S.Pd selaku guru di TK Sinar Harapan.

Untuk mengolah data yang diperoleh dari hasil observasi dan wawancara, teknik analisis data yang dilakukan antara lain reduksi data (pemilahan data sesuai kebutuhan), penyajian data (yang telah dipilah), dan penarikan kesimpulan ${ }^{20}$.

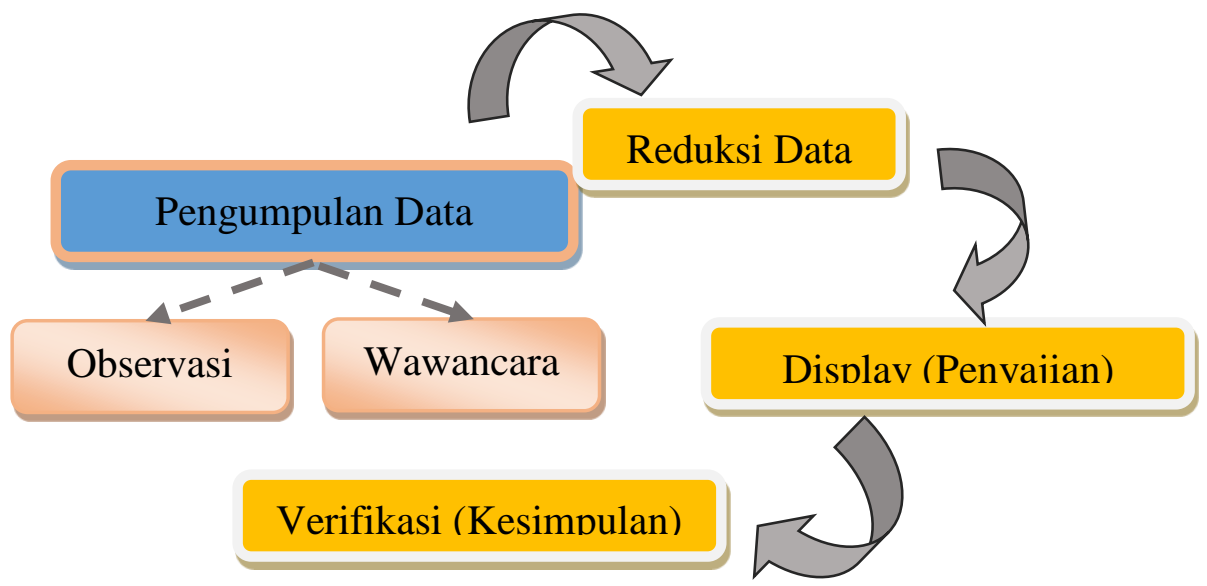

Gambar 1 Alur Teknik Analisis Data

e/viewFile/11345/10753\%0Ahttp://dx.doi.org/10.1016/j.sbspro.2015.04.758\%0Aww w.iosrjournals.org.

19 Taufik Hidayat, "Pembahasan Studi Kasus Sebagai Bagian Metodologi Penelitian," Jurnal Study Kasus, no. August (2019): 1-13, https://www.researchgate.net/publication/335227300_Pembahasan_Studi_Kasus_Seb agai_Bagian_Metodologi_Penelitian.

${ }_{20}$ Matthew B. Miles, A. Michael Huberman, and Johnny Saldana, "Qualitative Data Analysis: A Methods Sourcebook, 3/E," in Sage Publication, third (New York: SAGE Publications, 2013), 341. 
Gambar 1 menunjukkan proses pelaksanaan penelitian dalam menganalisis data. Awalnya, penulis melakukan pengumpulan data yang dilakukan melalui observasi langsung dan wawancara kepada narasumber (Kepala dan Guru TK Sinar Harapan). Setelah seluruh data terkumpul, maka dilakukan reduksi data untuk memilah data yang sesuai dengan topik penelitian untuk disajikan dalam hasil penelitian. Hasil penelitian yang didapat kemudian diringkas untuk mendapatkan kesimpulan akhir atau verifikasi data.

\section{Pembahasan}

\section{Perencaan Spiritual Educational di TK Sinar Harapan}

Perencaan pembelajaran dibutuhkan agar pelaksanaan kegiatan belajar mengajar berlangsung secara sistematis dan terstruktur dengan rapi. Selain itu, adanya sebuah perencaan dapat memperjelas tujuan dilaksanakannya pembelajaran. Setiap lembaga pendidikan pasti memiliki perencanaan pembelajaran sesuai dengan kurikulum yang digunakan.

Dalam hal ini, TK Sinar Harapan juga memiliki perencanaan pembelajaran guna merinci dan memperjelas sistematik serta tujuan dari diadakannya sebuah pembelajaran. Arifien ${ }^{21}$ menjelaskan bahwa TK Sinar Harapan juga memiliki perencanaan pembelajaran yang terdiri atas Program Tahunan (PROTA), program semester (PROMES), rencana pelaksanaan pembelajaran mingguan (RPPM), dan rencana pelaksanaan pembelajaran Harian (RPPH). Adapun PROMES, RPPM, dan RPPH harus disusun dan dirancang oleh setiap guru kelas agar dapat menyesuaikan dengan karakteristik, kebutuhan, dan perkembangan anak $\operatorname{didik}^{22}$.

Penyusunan perencanaan pembelajaran harus berpedoman pada kalender pendidikan yang mencakup tema-tema yang harus dicapai dalam satu tahun. Setelah program tahunan tersebut selesai disusun, guru dapat membuat perencanaan pembelajaran selama satu semester. Perencaanan semester merupakan penjabaran dari perencanaan tahunan sehingga sub tema, dan tujuan dari setiap kegiatan dapat lebih terperinci. Begitu pula dengan RPPM yang merupakan penjabaran dari perencanaan semester atau PROMES. Sementara RPPH merupakan penjabaran dari RPPH. Penjabaran-penjabaran tersebut diperlukan untuk merinci tema/sub tema materi, alat dan bahan, sistematika kegiatan, serta rencana penilaian dari

\footnotetext{
$21(2021)$

22 Theresia Alviani Sum and Emilia Graciela Mega Taran, "Kompetensi Pedagogik Guru PAUD Dalam Perencanaan Dan Pelaksanaan Pembelajaran," Jurnal Obsesi : Jurnal Pendidikan Anak Usia Dini 4, no. 2 (2020): 543, https://doi.org/10.31004/obsesi.v4i2.287.
} 
setiap kegiatan pembelajaran ${ }^{23}$. Dengan demikian, setiap pembelajaran yang dilakukan di TK Sinar Harapan selalu terencana dengan baik dan sistematis agar tujuan yang dibuat dapat tercapai secara maksimal.

\section{Spiritual Educational di TK Sinar Harapan}

TK Sinar Harapan merupakan sebuah lembaga tingkat PAUD yang berupaya untuk melejitkan kecerdasan ruhani anak didiknya. Dalam hal itu, TK Sinar Harapan mengembangkan sebuah model pembelajaran ruhani, yakni Spiritual Educational. Penerapan pembelajaran Spiritual Educational di TK Sinar Harapan terlihat dari beberapa kegiatan terencana sebagaimana berikut.

Pertama, membaca Asmaul Husna dan surat-surat pendek sebelum pelajaran dimulai. Agar tetap menyenangkan dan memicu motivasi belajar anak sebelum pelajaran dimulai, pembacaan Asmaul Husna dilakukan dengan mengikuti irama lagu. Sementara pembacaan suratsurat pendeknya dilakukan secara bergilir setiap hari. Apabila pada hari Senin membaca surat Al-Kaafirun, maka pada hari Selasa membaca surat An-Nashr. Begitu seterusnya ke belakang. Dengan terbiasa membaca Asmaul Husna dan surat-surat pendek, anak didik dapat mengenal 99 nama Allah serta mampu menghafal beberapa surat tanpa melakukan proses hafalan yang berat. Melalui pembacaan Asmaul Husna dan suratsurat pendek ini pula, guru TK Sinar Harapan mengajarkan anak didiknya untuk senantiasa mengingat Allah dan meminta pertolonganNya setiap kali hendak melakukan sesuatu.

Pembacaan Asmaul Husna dengan mengikuti irama lagu lebih tepat digunakan bagi anak usia dini sebab di usia tersebut anak akan merasa senang dan gembira apabila pembelajaran dilakukan sambil bermain, bercerita, atau bernyanyi ${ }^{24}$. Ketika pembacaan Asmaul Husna dilakukan dengan mengikuti irama lagu secara berulang-ulang, hal tersebut akan membuat anak didik mudah untuk menghafalnya. Menghafal Asmaul Husna dan surat-surat pendek dalam Al Quran perlu ditanamkan sejak kecil agar anak mengetahui serta mengenal keagungan

\footnotetext{
23 Yulianti S and Prihatin Sulistyo, "Pelatihan Penyusunan Perangkat Pembelajaran Anak Usia Dini Bagi Guru-Guru Paguyuban POS PAUD Di Wilayah Tlogomas," JPM Jurnal Pemberdayaan Masyarakat) 3, no. 1 (2018): 239-45, https://doi.org/10.21067/jpm.v3i1.2664.

${ }^{24}$ Mawardi and Sri Indayani, "Peningkatan Hafalan Asmaul Husna Melalui Strategi Bernyanyi Pada Siswa SD Plus Muhammadiyah Subulussalam Kota Subulussalam," Jurnal Pendidikan Indonesia 1, no. 2 (2020): 12-26.
} 
Tuhan-Nya ${ }^{25}$. Sisi positif lainnya, pembacaan surat-surat pendek dan Asmaul Husna dapat menjadi pembiasaan positif guna membentuk dan meningkatkan karakter anak ${ }^{26}$.

Kedua, praktik wudhu dan sholat Dhuha setiap hari Jumat. Pelaksanaan praktik wudhu dan sholat Dhuha dilakukan dengan tujuan untuk mengajarkan tata cara berwudhu dengan benar serta mengenalkan salah satu sholat sunnah kepada anak didik, yakni sholat Dhuha. Selain itu, praktik mingguan ini juga bermaksud untuk membiasakan anak didik untuk senantiasa berwudhu dengan benar sebelum melakukan sholat dan membiasakan anak didik untuk melakukan sholat Dhuha selain mengerjakan sholat lima waktu yang wajib. Tentunya, sholat Dhuha ini dilakukan secara berjamaah untuk melatih solidaritas serta kedisiplinan anak. Urfiani ${ }^{27}$ menambahkan, ketika anak sudah terbiasa melakukan suatu hal yang diajarkan agama, maka anak juga akan tumbuh menjadi pribadi yang senantiasa melakukan hal yang dibenarkan agama.

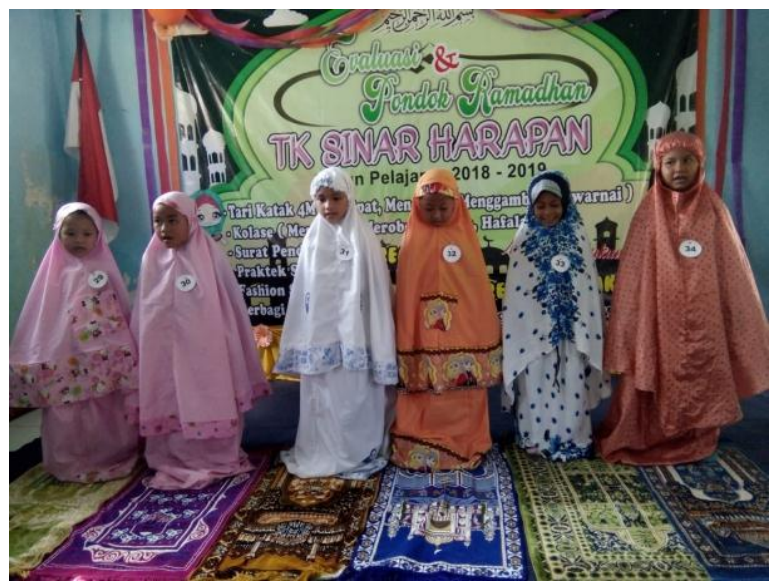

Gambar 2 Pelaksanaan Sholat Dhuha Berjamaah

25 Andrian Firdaus, "Pembiasaan Membaca Asmaul Husna Dalam Menanamkan Pengetahuan Keagamaan Pada Anak Di SDIT Abata Lombok (NTB)," Jurnal Al-Amin; Kajian Pendidikan Dan Sosial Kemasyarakatan 4 (2019): 115-36.

${ }^{26}$ Hafifah Mawaddah and Nur Aini Zaida, "Efektivitas Program Sekolah Ramah Anak Dalam Pembentukkan Karakter Positif Pada Anak Kelompok B Usia 5-6 Tahun Di RA Labschool IIQ Jakarta," Hamalatul Qur'an: Jurnal Ilmu-Ilmu Al Qur'an 2, no. 1 (2021): 1-6. 27 (2021) 
Pada Gambar 2 di atas terlihat anak didik TK Sinar Harapan sedang melakukan sholat Dhuha berjamaah pada hari Jumat. Pelaksanaan sholat Dhuha berjamaahdi pagi hari yang diawali dengan praktik wudhu ternyata dapat meningkatkan kecerdasan spiritual anak sebab pada daya konsentrasi anak di pagi hari sangat baik untuk ditumbuhkembangkan ${ }^{28}$. Dalam konteks ini, anak didik akan meniru apa yang dicontohkan oleh guru ketika berwudhu dan sholat Dhuha sehingga hal tersebut terekam dengan baik dalam otak anak. Mengajarkan praktik wudhu dan sholat Dhuha juga dapat mengajarkan anak untuk memahami pentingnya sholat Dhuha, yakni selalu mensyukuri segala nikmat Allah Subhaanabu wa Ta'alaa ${ }^{29}$. Tidak hanya itu, mengajarkan anak didik untuk melakukan sholat berjamaah dapat melatih kedisiplinan serta menanamkan nilai-nilai kebersamaan ${ }^{30}$.

Ketiga, berbagi sembako ketika Isra' Mi'raj dan berbagi zakat ketika Ramadhan. Pada saat terdapat hari besar Islam seperti Isra' Mi'raj maupun ketika Ramadhan, TK Sinar Harapan memperingatinya dengan berbagi sembako dan zakat kepada penduduk sekitar di samping memberi ceramah singkat kepada anak didik mengenai sejarah Isra' Mi'raj ataupun keutamaan serta keistimewaan bulan Ramadhan. Pembagian sembako dan zakat ini dilakukan sendiri oleh para murid TK Sinar Harapan. Sembako dan zakat tersebut didapat dari hasil sumbangan murid TK Sinar Harapan. Dengan melakukan bagi-bagi sembako dan zakat, murid TK Sinar Harapan diajarkan untuk saling berbagi dan peduli kepada orang lain. Hal tersebut berguna untuk menghilangkan sifat kikir dan sombong di hati anak.

Mengajarkan anak didik untuk saling berbagi juga termasuk dalam salah satu unsur kecerdasan spiritual. Berbagi sembako dan zakat akan melatih anak untuk berbuat baik dan menolong sesama. Hal itu yang kemudian membuat anak tumbuh menjadi pribadi bermoral baik dan

\footnotetext{
${ }^{28}$ Novita Sari and Dessi Andriani, "Pengaruh Sholat Dhuha Terhadap Kecerdasan Spiritual Anak Kelompok B Usia 5-6 Tahun Di TK Ar-Rahmah Tanjung Atap," PERNIK: Jurnal Pendidikan Anak Usia Dini 3, no. 2 (2020): 166, https://doi.org/10.31851/pernik.v3i1.4185.

29 Aisya Fajariska, Sutrisna, and Sri Nugroho Jati, "Pelaksanaan Pembelajaran Sholat Dhuha Melalui Metode Praktik Langsung Pada Anak Usia 5-6 Tahun Di Taman KanakKanak Islam Terpadu Al-Karima Kabupaten Kubu Raya," Edukasi: Jurnal Ilmiah Pendidikan Anak Usia Dini 5, no. 2 (2017): 245, http://digilib.unila.ac.id/4949/15/BAB II.pdf.

${ }^{30}$ Yusup Karjanto, "Signifikasi Shalat Berjamaah Terhadap Kedisiplinan Siswa Di Madrasah Aliyah An-Nafiah Banjaran Baureno Bojonegoro," EDURELIGLA: Jurnal Keagamaan Dan Pembelajarannya 2, no. 1 (2018): 36-48.
} 
religius ${ }^{31}$. Lebih jauh lagi, Bali berpendapat bahwa melibatkan anak dalam kegiatan-kegiatan sosial seperti ini dapat melatih keterampilan sosial agar anak mampu memperoleh hubungan yang baik dalam berinteraksi dengan orang lain ${ }^{32}$. Ketika anak memiliki keterampilan sosial, maka anak juga akan terbiasa untuk berempati dan peduli terhadap orang lain di sekitarnya ${ }^{33}$. Hal ini penting untuk dipupuk sejak dini agar hati anak tidak keras.

Keempat, berkunjung ke TWSL (Taman Wisata Studi Lingkungan) dan Museum. Kunjungan ke TWSL dan Museum ini dilakukan sekali dalam satu semester sebagai salah satu bentuk wisata ruhani bagi anak. TWSL merupakan sebuah kebun binatang kecil yang berada di kota Probolinggo. Untuk menuju TWSL dan Museum, TK Sinar Harapan biasa menyewa kereta anak sehingga murid-murid merasa senang. Kunjungan ini bertujuan untuk mengenalkan anak pada aneka ragam makhluk ciptaan Allah serta peninggalan tokoh-tokoh pahlawan Probolinggo selama memperjuangkan kemerdekaan dan mengembangkan kota Probolinggo.

Melalui kunjungan ini (TWSL), Umami ${ }^{34}$ menyatakan bahwa murid TK Sinar Harapan akan belajar untuk mengagumi kebesaran dan keagungan Allah. Sementara dengan mengenal tokoh pahlawan dan menceritakan perjuangan tokoh-tokoh tersebut dapat melatih daya ingat dan imajinasi anak. Keduanya merupakan upaya untuk melejitkan kecerdasan ruhani anak sebab wisata ruhani mampu menggugah jiwa. Kesan takjub pada ciptaan Allah itulah yang memicu imajinasi anak untuk menikmati pemandangan alam melalui perspektif ruhaninya ${ }^{35}$.

Kelima, praktik manasik haji. Praktik ini dilakukan sekali dalam setiap tahun. Adapun pelaksanaan praktik manasik haji ini dilakukan di Wisata Religi Replika Miniatur Ka'bah yang berada di Kabupaten Probolinggo. Pada praktik ini, murid TK Sinar Harapan diajarkan cara

31 Muammar Qadafi, "Kolaborasi Guru Dan Orang Tua Dalam Mengembangkan Aspek Moral Agama Anak Usia Dini," AWLADY: Jurnal Pendidikan Anak 5, no. 1 (2019): 1-19, www.syekhnurjati.ac.id/jurnal/index.php/awlady.

32 Eva luthfi Fakhru Ahsani and Nur Rufidah Azizah, "Implementasi Literasi Budaya Dan Kewargaan Untuk Mengembangkan Keterampilan Sosial Siswa Madrasah Ibtidaiyah Di Tengah Pandemi," Jurnal Pendidikan Kewarganegaraan 11, no. 01 (2021): 7, https://doi.org/10.20527/kewarganegaraan.v11i01.10317.

33 Novia Rahmadianti, "Pemahaman Orang Tua Mengenai Urgensi Bermain Dalam Meningkatkan Perkembangan Sosial Anak Usia Dini," Early Childhood: Jurnal Pendidikan 4, no. 1 (2020): 57-64, https://doi.org/10.35568/earlychildhood.v4i1.717.

34 (2021)

35 Santi Sulandari, Mei Wijayanti, and Ria Dessy Pornama Sari, "Keterlibatan Lansia Dalam Pengajian: Manfaat Spiritual, Sosial, Dan Psikologis," Indigenous 1, no. 2 (2017): 99-110. 
melakukan ibadah haji, mulai dari mengenalkan hukum, syarat wajib, rukun, hingga keutamaan haji. Tentunya, murid TK Sinar Harapan juga diharuskan memakai pakaian ihram. Pakaian ihram yang dipakai merupakan inventaris TK Sinar Harapan sebagai media pembelajaran. Praktik manasik haji di miniatur Ka'bah ini juga termasuk wisata ruhani, namun dengan pembelajaran khusus agama, yakni pengenalan rukun Islam yang kelima.

Praktik manasik haji sebagaimana yang dilakukan oleh TK Sinar Harapan merupakan cara lain untuk melejitkan kecerdasan ruhani anak, yakni dengan melibatkan anak dalam kegiatan ritual kegamaan. Hal tersebut efektif untuk dilakukan sebab dapat memberikan kesan khusus pada anak tanpa melalui nasihat spiritual yang terkadang membuat anak merasa bosan ${ }^{36}$. Selain itu, pengenalan metode manasik haji bagi anak dapat membentuk karakter baik dan berbudi luhur. Sebab, pelaksanaan haji juga mengingatkan seorang muslim terhadap kisah Nabi Ibrahim dalam membangun Ka'bah ${ }^{37}$.

Keenam, ikut serta dalam pawai Muharram dan pentas PAIS (Pendidikan Agama Islam). Untuk memicu semangat serta mengasah bakat minat anak, guru TK Sinar Harapan selalu mengikutsertakan anak didiknya dalam kegiatan pawai Muharram dan pentas PAIS. Pada pawai Muharram yang diadakan oleh IGTKI (Ikatan Guru Taman Kanakkanak Indonesia) ini, anak-anak diminta untuk berpakaian muslim dengan tema-tema yang unik. Sementara pentas PAIS merupakan perlombaan yang diadakan oleh Departemen Agama kota Probolinggo dengan daftar lomba seperti menyanyi lagu islami, mewarnai kaligrafi, puisi berantai, tausiyah, dan hafalan surat pendek.

\footnotetext{
${ }^{36}$ Mufidah Yusroh, Ellyana Ilsan, and Eka Putri, "Pelatihan Manasik Haji Pada AnakAnak Bentuk Penanaman Nilai-Nilai Agama Usia Dini," Abdi Kami: Jurnal Pengabdian Kepada Masyarakat 2, no. 1 (2019): 50-60.

${ }^{37}$ M. Subhan Ansori and Siti Uswatun Kasanah, "Pemahaman Dan Keterampilan Ibadah Haji Bagi Peserta Didik, Guru, Dan Wali Murid Melalui Pembelajaran Praktek Manasik Haji Untuk Anak Usia Dini," Jurnal Pengabdian Dan Pemberdayaan Nusantara 1, no. 1 (2019): 14-24.
} 


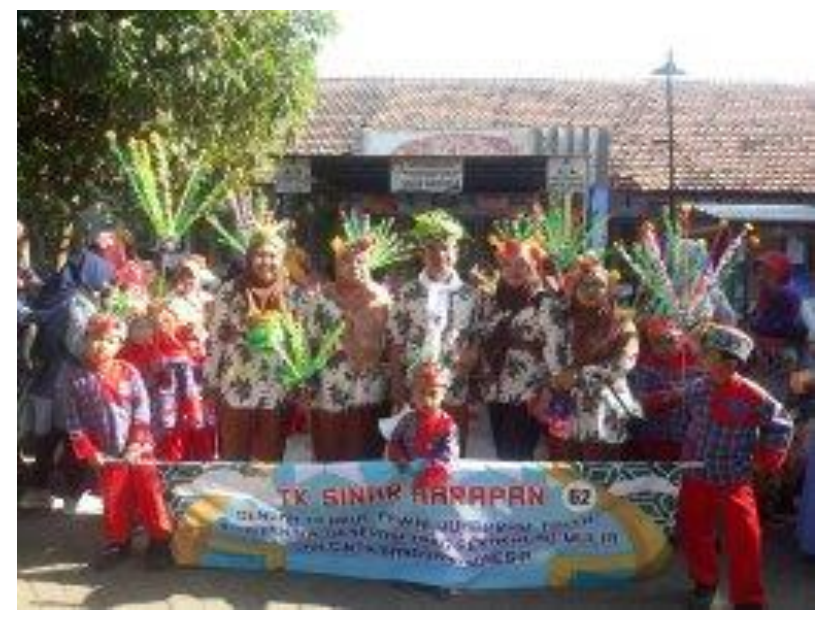

Gambar 3 Pawai Muharram

Gambar 3 menunjukkan keikutsertaan anak didik TK Sinar Harapan dalam kegiatan Pawai Muharram yang diadakan oleh IGTKI. Keikutsertaan anak didik dalam berbagai kegiatan Islami juga dapat menimbulkan perasaan gembira. Bagi anak PAUD, keikutsertaan dalam kegiatan pawai dan lomba-lomba Islami dapat menstimulasi kecerdasan majemuk, khususnya ruhani anak ${ }^{38}$. Namun, yang peling penting adalah kegiatan-kegiatan tersebut dapat menjadi sarana bersosialisasi dengan teman sebaya. Melalui kegiatan pawai dan lomba-lomba Islami ini pula, anak dididik untuk kreatif dan inovatif dalam memeriahkan hari besar Islam ${ }^{39}$. Kegiatan tersebut juga dapat melatih kekompakan dalam tim, kemampuan menyampaikan ide kreativitas atau berkomunikasi ${ }^{40}$. Dengan begitu, anak akan belajar untuk menghargai dan menghayati Perayaan Hari Besar Islam (PHBI) dengan cara yang asyik dan menyenangkan.

Ketujuh, menceritakan tokoh-tokoh Islam dan menyanyikan lagulagu Islami. Berbeda dengan keenam kegiatan sebelumnya, kegiatan yang

\footnotetext{
38 Sri Slamet, "Stimulasi Perkembangan Anak Usia Dini Melalui Kegiatan Mewarnai Dan Hafalan Al Quran," Warta LPM 24, no. 1 (2020): 59-68, https://doi.org/10.23917/warta.v24i1.9917.

${ }^{39}$ Deden HMS, "FIS (Fun-Innovative-Spritual): Manajemen Pemasaran Di KB. Fun Islamic School Purworejo," Golden Age: Jurnal Ilmiah Tumbuh Kembang Anak Usia Dini 5, no. 1 (2020): 1-10, https://doi.org/10.14421/jga.2020.1-10.

${ }^{40} \mathrm{~S}$ Wardiningsih et al., "Efek Perlombaan Kreativitas Sebagai Upaya Meningkatkan Komunikasi Hubungan Personal AntarKeluarga-Keluarga Di TK Islam An-Nur Pada Masa Pandemi Covid ...," Jurnal Karya Untuk ... 2, no. 2 (2021): 160-73, http://www.journal.starki.id/index.php/JKuM/article/view/621.
} 
ketujuh ini tidak terprogram secara khusus. Akan tetapi, guru TK Sinar Harapan melakukannya sewaktu-waktu di sela pembelajaran. Dalam hal ini, guru TK Sinar Harapan akan sesekali menceritakan tokoh Islam sesuai tema pembelajaran yang sedang dibahas. Misalnya, apabila tema yang sedang dibahas adalah Profesi, maka guru akan menceritakan kisah Sayyidina Umar bin Khattab yang menjadi khalifah Islam, namun sahabat nabi ini selalu dekat dengan rakyatnya, bahkan tidak segan untuk membantu rakyatnya yang membutuhkan bantuan ketika bertemu di jalan. Kisah teladan ini sengaja disisipkan agar murid terinspirasi oleh tokoh-tokoh yang selalu dekat dengan Allah. Begitu pula dengan lagulagu islami yang dinyanyikan bersama, lagu yang dipilih juga disesuaikan dengan tema pembelajaran yang sedang dibahas.

Menceritakan tokoh Islam di sela pembelajaran dapat menjadi media untuk menanamkan nilai-nilai agama pada anak. Dalam hal ini, cerita Islami setidaknya memiliki tiga nilai penting, yakni nilai keimanan, ibadah, dan akhlak ${ }^{41}$. Selain kisah Islami, menyanyikan lagu Islami juga dapat menimbulkan perasaan hangat dan vitalitas yang dapat memberikan motivasi pada anak untuk memperbaiki perilakunya dan memperbarui tekad sesuai makna lagu yang dinyanyikan ${ }^{42}$. Dalam upaya melejitkan kecerdasan ruhani anak, guru harus mampu melakukan inovasi dan kreasi agar anak didik tidak bosan ketika mendapat mendapat pembelajaran moral dan agama ${ }^{43}$. Dengan begitu, menceritakan tokoh dan menyanyikan lagu Islami dapat menjadi inovasi yang tepat dan menarik. Bahkan, ketika seorang guru memberikan selingan pembelajaran dengan cara menceritakan tokoh Islam atau mengajak anak untuk menyanyikan lagu-lagu Islami merupakan salah satu bentuk bahwa guru memahami kebutuhan anak didiknya sehingga guru tersebut akan semakin dicintai oleh anak didik ${ }^{44}$.

\footnotetext{
${ }^{41}$ Laily Fitriani, "Internalisasi Nilai-Nilai Karakter Islami Pada Anak Usia Dini Melalui Metode Berkisah," in Proceedings of THe 3rd Annual Conference on Islamic Early Childhood Education, 2018, 247-56.

${ }^{42}$ V Oktarina and A T Nurtiani, "Peningkatan Kecerdasan Spiritual Anak Melalui LaguLagu Islami Di Kelompok B Ra Al-Muslimat Lueng Bata Banda Aceh," Jurnal Buah Hati III (2016), https://ejournal.bbg.ac.id/buahhati/article/view/545.

43 Atin Fatimah, "Prosiding Seminar Nasional Pg Paud Untirta 2017 Ketahanan Pangan Keluarga Dalam Rangka," Seminar Nasional PAUD, no. 2017 (2017), http://semnaspgpaud.untirta.ac.id/index.php/\%0Ae-ISSN.

${ }^{44}$ Yazidul Busthomi and Syamsul A'dlom, "Sebelas Modal Agar Menjadi Guru Yang Dicintai Oleh Peserta Didiknya," Murobbi: Jurnal Ilmu Pendidikan 5, no. 2 (2021): 181200.
} 


\section{Evaluasi Model Pembelajaran Spiritual Educational}

Untuk mengetahui keberhasilan capaian model pembelajaran Spiritual Educational, guru TK Sinar Harapan juga mengadakan evaluasi. Ariefin ${ }^{45}$ mengatakan bahwa evaluasi pelaksanaan Spiritual Educational di TK Sinar Harapan dilakukan setiap akhir semester. Evaluasi di TK Sinar Harapan dilakukan dengan cara menggelar perlombaan antarkelas. Lomba yang digelar antara lain lomba sholat Dhuha, menyanyi lagu Islami, fashion busana muslim, dan hafalan surat-surat pendek. Melalui perlombaan ini, guru dapat mengetahui sejauh mana kemampuan anak didiknya dalam memahami pembelajaran Islami yang telah diterapkan selama satu semester.

Selain melakukan evaluasi di akhir semester, TK Sinar Harapan juga membuat rancangan evaluasi yang termuat dalam RPPH. Evaluasi tersebut pada umunya berupa penilaian sikap (afektif). Adanya evaluasi seperti demikian berfungsi sebagai upaya mengetahui dan mengoreksi proses pembelajaran agar dapat meningkatkan kualitas pembelajaran ${ }^{46}$.

\section{Penutup}

Penelitian ini fokus pada penerapan Spiritual Educational sebagai sebuah model pembelajaran guna melejitkan kecerdasan ruhani anak yang diterapkan di TK Sinar Harapan, Probolinggo. Melalui model pembelajaran Spiritual Educational, TK Sinar Harapan membuat beberapa kegiatan pembelajaran Islami secara rutin. Kegiatan pembelajaran Islami tersebut antara lain membaca Asmaul Husna dan surat-surat pendek sebelum pelajaran dimulai, praktik wudhu dan sholat Dhuha setiap hari Jumat, berbagi sembako ketika Isra' Mi'raj dan berbagi zakat ketika Ramadhan, berkunjung ke TWSL (Taman Wisata Studi Lingkungan) dan Museum, praktik manasik haji, ikut serta dalam pawai Muharram dan pentas PAIS (Pendidikan Agama Islam), menceritakan tokoh-tokoh Islam dan menyanyikan lagu-lagu Islami.

Berbagai kegiatan pembelajaran Islami tersebut diterapkan guna mengasah sisi ruhani anak sehingga kecerdasan ruhani mereka dapat melejit ketika kegiatan tersebut menjadi sebuah rutinitas. Implikasi dari penelitian ini menunjukkan bahwa dibutuhkan beragam kegiatan dan pendekatan yang menyenangkan namun terstruktur serta dilaksanakan secara rutin untuk dapat melejitkan kecerdasan ruhani anak. Tentunya, model pembelajaran ini tidak dapat digeneralisir pada semua lembaga sebab terdapat perbedaan kondisi lingkungan belajar.

\footnotetext{
45 (2021b)

46 Alya Amarul Hani, "Evaluasi Pembelajaran Pada PAUD,” Care 7, no. 1 (2019): 52-56.
} 


\section{Daftar Pustaka}

Ahsani, Eva luthfi Fakhru, and Nur Rufidah Azizah. "Implementasi Literasi Budaya Dan Kewargaan Untuk Mengembangkan Keterampilan Sosial Siswa Madrasah Ibtidaiyah Di Tengah Pandemi." Jurnal Pendidikan Kewarganegaraan 11, no. 01 (2021): 7. https://doi.org/10.20527/kewarganegaraan.v11i01.10317.

Ansori, M. Subhan, and Siti Uswatun Kasanah. "Pemahaman Dan Keterampilan Ibadah Haji Bagi Peserta Didik, Guru, Dan Wali Murid Melalui Pembelajaran Praktek Manasik Haji Untuk Anak Usia Dini." Jurnal Pengabdian Dan Pemberdayaan Nusantara 1, no. 1 (2019): 14-24.

Ariefin, Syamsul. "Wawancara." In Kepala TK Sinar Harapan, 6, 2021. "Wawancara." In Kepala TK Sinar Harapan, 2021.

Asti, Inawati. "Strategi Pengembangan Moral Dan Nilai Agama Untuk Anak Usia Dini." Jurnal Pendidikan Anak 3, no. 1 (2017): 51-64.

At-Tahrim. "Al Quran." In Penerbit Jabal, 148:148-62, 2010.

Aziz, Safrudin. "Pendidikan Spiritual Berbasis Sufistik." Dialogia: Jurnal Studi Islam Dan Sosial 15, no. 1 (2017): 131-50.

Busthomi, Yazidul, and Syamsul A'dlom. "Sebelas Modal Agar Menjadi Guru Yang Dicintai Oleh Peserta Didiknya.” Murobbi: Jurnal Ilmu Pendidikan 5, no. 2 (2021): 181-200.

Fajariska, Aisya, Sutrisna, and Sri Nugroho Jati. "Pelaksanaan Pembelajaran Sholat Dhuha Melalui Metode Praktik Langsung Pada Anak Usia 5-6 Tahun Di Taman Kanak-Kanak Islam Terpadu Al-Karima Kabupaten Kubu Raya." Edukasi: Jumal Ilmiah Pendidikan Anak Usia Dini 5, no. 2 (2017): 245. http://digilib.unila.ac.id/4949/15/BAB II.pdf.

Farida, Nugrahani. Metode Penelitian Kualitatif Dalam Penelitian Pendidikan Babasa. Grasindo. Vol. 1, 2014. http://ejournal.usd.ac.id/index.php/LLT\%0Ahttp://jurnal.untan.ac.id/i ndex.php/jpdpb/article/viewFile/11345/10753\%0Ahttp://dx.d oi.org/10.1016/j.sbspro.2015.04.758\%0Awww.iosrjournals.org.

Fatimah, Atin. "Prosiding Seminar Nasional Pg Paud Untirta 2017 Ketahanan Pangan Keluarga Dalam Rangka." Seminar Nasional PAUD, no. 2017 http://semnaspgpaud.untirta.ac.id/index.php/\%0Ae-ISSN.

Firdaus. "Membangun Kecerdasan Spiritual Islami Anak Sejak Dini." AlDrikra 10, no. 1 (2016): 99-122.

Firdaus, Andrian. "Pembiasaan Membaca Asmaul Husna Dalam Menanamkan Pengetahuan Keagamaan Pada Anak Di SDIT Abata Lombok (NTB)." Jurnal Al-Amin; Kajian Pendidikan Dan 
Sosial Kemasyarakatan 4 (2019): 115-36.

Fitriani, Laily. "Internalisasi Nilai-Nilai Karakter Islami Pada Anak Usia

Dini Melalui Metode Berkisah." In Proceedings of THe 3rd Annual

Conference on Islamic Early Childhood Education, 247-56, 2018.

Hamid, Abdul, and Andi Fitriani. "Strategi Pendidikan Spiritual Dalam

Mengantisipasi Dampak Globalisasi Pada Masyarakat.” Jurnal AlAthfal 1, no. 2 (2019): 55-65.

Hani, Alya Amarul. "Evaluasi Pembelajaran Pada PAUD." Care 7, no. 1 (2019): 52-56.

Hidayat, Taufik. "Pembahasan Studi Kasus Sebagai Bagian Metodologi Penelitian." Jurnal Study Kasus, no. August (2019): 1-13. https://www.researchgate.net/publication/335227300_Pembaha san_Studi_Kasus_Sebagai_Bagian_Metodologi_Penelitian.

HMS, Deden. "FIS (Fun-Innovative-Spritual): Manajemen Pemasaran Di

KB. Fun Islamic School Purworejo." Golden Age: Jurnal Ilmiah Tumbuh Kembang Anak Usia Dini 5, no. 1 (2020): 1-10. https://doi.org/10.14421/jga.2020.1-10.

Karjanto, Yusup. "Signifikasi Shalat Berjamaah Terhadap Kedisiplinan Siswa Di Madrasah Aliyah An-Nafiah Banjaran Baureno Bojonegoro." EDURELIGLA: Jurnal Keagamaan Dan Pembelajarannya 2, no. 1 (2018): 36-48.

Mariana, Nina, Abdul Azis, and Iwan Setiawan. "Pengembangan Kecerdasan Spritual Anak Usia Dini Melalui Homeschooling." Tarbiyah Al Aulad 4, no. 1 (2019): 27-44.

Mawaddah, Hafifah, and Nur Aini Zaida. "Efektivitas Program Sekolah Ramah Anak Dalam Pembentukkan Karakter Positif Pada Anak Kelompok B Usia 5-6 Tahun Di RA Labschool IIQ Jakarta." Hamalatul Qur'an: Jurnal Ilmu-Ilmu Al Qur'an 2, no. 1 (2021): 1-6.

Mawardi, and Sri Indayani. "Peningkatan Hafalan Asmaul Husna Melalui Strategi Bernyanyi Pada Siswa SD Plus Muhammadiyah Subulussalam Kota Subulussalam.” Jurnal Pendidikan Indonesia 1, no. 2 (2020): 12-26.

Miles, Matthew B., A. Michael Huberman, and Johnny Saldana. "Qualitative Data Analysis: A Methods Sourcebook, 3/E." In Sage Publication, Third., 341. New York: SAGE Publications, 2013. Nirwani Jumala, Nirwani Jumala, and Abubakar Abubakar. "Internalisasi

Nilai-Nilai Spiritual Islami Dalam Kegiatan Pendidikan.” Jurnal Serambi Ilmu 20, no. 1 (2019): 160. https://doi.org/10.32672/si.v20i1.1000.

Nurlaili. "Upaya Guru Dalam Meningkatkan Kecerdasan Spiritual Dengan Model Pembelajaran Sentra Di PAUD Mirage Gune.” Jurnal Al Fitrah 2, no. 1 (2018): 229-41. 
Oktapiani, Marliza. "TINGKAT KECERDASAN SPIRITUAL DAN KEMAMPUAN MENGHAFAL AL-QUR'AN.” Tadz̧bib Akblak 01 (2020): 96.

Oktarina, V, and A T Nurtiani. "Peningkatan Kecerdasan Spiritual Anak Melalui Lagu-Lagu Islami Di Kelompok B Ra Al-Muslimat Lueng Bata Banda Aceh." Jurnal Buah Hati III (2016). https://ejournal.bbg.ac.id/buahhati/article/view/545.

Qadafi, Muammar. "Kolaborasi Guru Dan Orang Tua Dalam Mengembangkan Aspek Moral Agama Anak Usia Dini." AWLADY: Jurnal Pendidikan Anak 5, no. 1 (2019): 1-19. www.syekhnurjati.ac.id/jurnal/index.php/awlady.

Rahmadianti, Novia. "Pemahaman Orang Tua Mengenai Urgensi Bermain Dalam Meningkatkan Perkembangan Sosial Anak Usia Dini." Early Childhood: Jurnal Pendidikan 4, no. 1 (2020): 57-64. https://doi.org/10.35568/earlychildhood.v4i1.717.

Rosmayanti, Ervi. "Upaya Penggunaan Model Pembelajaran Jarak Jauh Untuk Meningkatkan Aspek Spiritual Siswa SD 2 Medini." Al Hikmah: Journal of Education 1, no. 1 (2020): 85-92. http://yphn.ac.id/ejournal/index.php/Alhikmah/index.

S, Yulianti, and Prihatin Sulistyo. "Pelatihan Penyusunan Perangkat Pembelajaran Anak Usia Dini Bagi Guru-Guru Paguyuban POS PAUD Di Wilayah Tlogomas." JPM Jurnal Pemberdayaan Masyarakat) 3, no. 1 (2018): 239-45. https://doi.org/10.21067/jpm.v3i1.2664.

Sari, Novita, and Dessi Andriani. "Pengaruh Sholat Dhuha Terhadap Kecerdasan Spiritual Anak Kelompok B Usia 5-6 Tahun Di TK Ar-Rahmah Tanjung Atap." PERNIK: Jurnal Pendidikan Anak Usia Dini 3, no. 2 (2020): 166. https://doi.org/10.31851/pernik.v3i1.4185.

Slamet, Sri. "Stimulasi Perkembangan Anak Usia Dini Melalui Kegiatan Mewarnai Dan Hafalan Al Quran.” Warta LPM 24, no. 1 (2020): 59-68. https://doi.org/10.23917/warta.v24i1.9917.

Sulandari, Santi, Mei Wijayanti, and Ria Dessy Pornama Sari. "Keterlibatan Lansia Dalam Pengajian: Manfaat Spiritual, Sosial, Dan Psikologis." Indigenous 1, no. 2 (2017): 99-110.

Sum, Theresia Alviani, and Emilia Graciela Mega Taran. "Kompetensi Pedagogik Guru PAUD Dalam Perencanaan Dan Pelaksanaan Pembelajaran." Jurnal Obsesi : Jurnal Pendidikan Anak Usia Dini 4, no. 2 (2020): 543. https://doi.org/10.31004/obsesi.v4i2.287.

Suradarma, Ida Bagus. "Revitalisasi Nilai-Nilai Moral Keagamaan Di Era Globalisasi Melalui Pendidikan Agama." Dharmasmrti: Jurnal Ilmu 
Agama Dan Kebudayaan 18, no. 2 (2018): 50-58. https://doi.org/10.32795/ds.v9i2.146.

Suyadi. "Cerdas Dengan Spiritual Educational Games." In Saufa, 15, 2015.

Umami, Vivin. "Wawancara." In Guru TK Sinar Harapan, 3, 2021.

Urfiani. "Wawancara." In Guru TK Sinar Harapan, 4, 2021.

Utama, Ferdian. "ESQ Way 165: Alternatif Metode Pengembangan Kecerdasan Emosi Dan Spiritual Anak." Journal of Early Childhood Care and Education 1, no. 1 (2018): 7. https://doi.org/10.26555/jecce.v1i1.59.

Wafiqni, Nafia, and Siti Nurani. "Model Pembelajaran Tematik Berbasis Kearifan Lokal." Al-Bidayah: Jurnal Pendidikan Dasar Islam 1, no. 2 (2018). https://doi.org/10.31227/osf.io/yv5u2.

Wahyudi, Dedi, and Nelly Agustin. "AKIDAH AKHLAK DENGAN MENGGUNAKAN MODEL PEMBELAJARAN BERBASIS NATURALISTIK EKSISTENSIAL SPIRITUAL PENDAHULUAN Berkembangnya Ilmu Pengetahuan Dan Teknologi Membawa Manusia Dalam Persaingan Global . Salah Satu Cara Yang Dapat Ditempuh Oleh Suatu Negara Agar." AlTadrkizyah: Jurnal Pendidikan Islam 9, no. I (2018): 37-59.

Wardiningsih, S, S Sitinah, S Hutabarat, and ... "Efek Perlombaan Kreativitas Sebagai Upaya Meningkatkan Komunikasi Hubungan Personal AntarKeluarga-Keluarga Di TK Islam An-Nur Pada Masa Pandemi Covid ...." Jurnal Karya Untuk ... 2, no. 2 (2021): 160-73.

http://www.journal.starki.id/index.php/JKuM/article/view/621. Wiyani, Novan Ardy. "Optimalisasi Kecerdasan Spiritual Bagi Anak Usia Dini Menurut Abdullah Nashih Ulwan.” ThufuLA: Jurnal Inovasi Pendidikan Guru Raudhatul Athfal, 2017. https://doi.org/10.21043/thufula.v4i2.2009.

Wulandari, Fitria, Tatang Hidayat, and Muqowim. "Konsep Pendidikan Holistik Dalam Membina Karakter Islami." Murobbi: Jurnal Ilmu Pendidikan 5, no. 2 (2021): 157-80.

Yusroh, Mufidah, Ellyana Ilsan, and Eka Putri. "Pelatihan Manasik Haji Pada Anak-Anak Bentuk Penanaman Nilai-Nilai Agama Usia Dini." Abdi Kami: Jurnal Pengabdian Kepada Masyarakat 2, no. 1 (2019): 50-60. 
